\title{
Wheelset/rail geometric characteristics and contact forces assessment with regard to angle of attack
}

\author{
Tomáš Lack, Juraj Gerlici *, Pavol Št’astniak \\ University of Žilina, Faculty of Mechanical Engineering, Department of Transport and Handling \\ Machines, Univerzitná 8215/1, 01026 Žilina, Slovak Republic
}

\begin{abstract}
The geometric relation between a wheelset and a rail is assessed with the help of geometric characteristics. Geometric characteristics are: equivalent conicity function, delta $\mathrm{r}$ function placement of contact points of a wheelset and a rail, tangent gamma function and effective conicity. It turned out that these characteristics are at present the most important not only for the judgment of ride characteristics of a vehicle on the rail but also for the wearing of wheel treads and rail heads, i.e., for the assessment of the track and vehicles in order to find out the current state and for the assessment of changes of the wheels and rails profile shapes in order to improve the current state too. The process of geometric characteristic assessment of a wheelset and rail with regard to angle of attack, as well as contact forces are analysed in the article.
\end{abstract}

Keywords: geometric characteristics, wheel and rail contact, contact forces, angle of attack, geometric characteristics values comparison

\section{Introduction}

Wheelset and rail geometric characteristics help to specify the geometric binding of a wheelset and rail. With the help of them, it is possible relatively quickly to assess some parameters of the binding which help to estimate as a vehicle or better to say a wheelset can behave in a real operation.

We understand under the name of geometric characteristics the following: contact points distribution between a wheel and rail at a lateral movement of wheels profiles of a wheelset over rail heads profiles, delta $r$ function, tangent gamma function and equivalent conicity function. The basic presupposition for the characteristics evaluation is detailed knowledge of a wheel and rail profiles geometric shape.

To make the information complete, it is necessary to mention separate geometric characteristics. On the base of their shape we will suggest a railway wheel profile shape (to the given rail profile) or a rail head profile shape (to the supposed railway wheel shape).

They are as follows.

\footnotetext{
* Corresponding author: juraj.gerlici@fstroj.uniza.sk

Reviewers: Kateryna Kravchenko, Maciej Bodnicki
} 
Contact points between wheel and rail determine the contact points position at a wheel profile lateral movement over the rail profile. If we can presuppose, that left and right wheel profiles (as well as rail profiles) are identical, the final curve course is symmetrical with regard to the rail axis.

Delta $r$ function is a difference between an instant diameter of running of one wheel of a wheelset and instant diameter of running (course) of other wheel of a wheelset at the lateral movement of a wheelset on a rail. The Delta $r$ function course shape indicates the rotating tendency of a wheelset at its lateral movement in a rail or kinematics running ability of a wheelset through the track arc.

Tangens gamma function is a difference between the value of the normal line tangent angle of the tangential contact area in the contact point and vertical axes of a rail. It determinates the rate of binding intensity which comes back the wheelset after its lateral deviation into a centred equilibrium position on the rail. The tangent gamma function has (like the delta $r$ function) anti-symmetrical course for the same wheels and rails profiles and it crosses the horizontal coordinate axis in its zero point.

Equivalent conicity is a reference conicity which equals the curving profile of a wheel when taking into consideration the amplitude of a coned wheel movement. According to the definition of UIC519 it is such conicity of a simple cone wheelset profile which the wheelset should possess in order to have the same kinematics characteristics as a wheelset with a curved profile at a certain oscillation amplitude.

The angle of attack and the angle of tilt of of the wheelset, which originated by a different instant diameter of rolling, influences the size and shape of geometrical characteristics. In the following text, let us suppose that the wheelset moves on the rail under the angle of attack which not equals zero grade.

\section{Geometric characteristics at the non-zero angle of attack}

Under optimal rolling conditions, when the wheelset is in center pozition on the track and axis of the wheelset and axis of the track are right-angled, wheels rolling on the rails on the nominal radius of the wheels at the angle of attack $\alpha=0^{\circ}$.

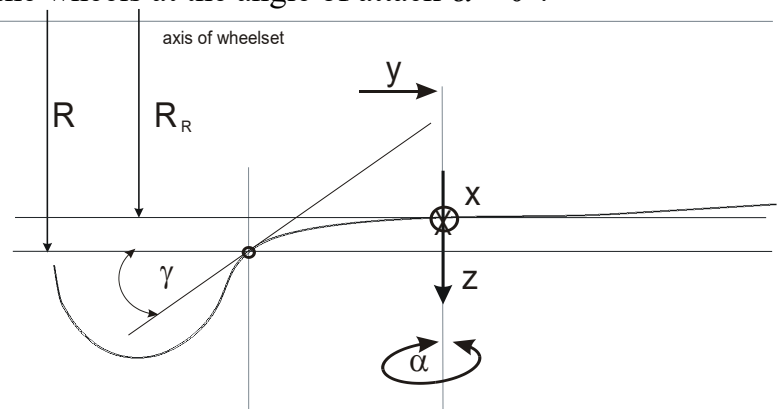

Fig. 1. Wheel profile with marked coordinates before transformation of geometry according to the angle of attack $\alpha$

In the case of a transverse displacement of the wheelset in the track (conical wheel surfaces) there is a change in instantaneous radii of rolling and to the tendency of the wheelset to perform movement in the arc. The axis of the wheelset is no longer perpendicular to the track axis, but is rotated under the angle of attack $\alpha$.

In the following consideration let's assume, that in the transverse displacement of the wheelset occurred in rotation about the $x$ axis by the value of the angle of attack $\alpha$. The plane of the wheel profile with normal line (initially parallel to the axis of the track) is rotated by the angle of attack. The geometry of the wheel profile changes with respect to the original 
shape (from the point of view of the plane perpendicular to the axis of track). In the plane of the wheel profile is located the contact point of the wheel and rail. Since the position of the rail profile remains unchanged, so the contact is carried out in a position on the rail that is offset in the $x$ direction.

Suppose, that the wheel will rotate by an angle $\alpha$ around the $z$ axis. For transverse displacement of the wheelset, which caused its rotation, there is a contact point between the wheel and the rail. This point represents the immediate rolling radius $R$. Dimension of the immediate rolling radius is given by the sum of values of the nominal radius of the wheel $R_{R}$ and $z$ value.

$$
\mathrm{R}=\mathrm{R}_{\mathrm{R}}+\mathrm{z}
$$

In the place of contact between wheel and rail is the touch plane inclined at an angle $\gamma$.

To simplify the expression of transformation relations, we can use the expression $P$.

$$
\mathrm{P}=1-\left(1+\operatorname{tg}^{2} \gamma\right) \cdot \sin ^{2} \alpha
$$

The term $P$ simplifies the writing of the mathematical expression of the transformation. For the calculation it has a practical meaning in the possibility of controlling to the nonnegativity of the expression for further calculation. Coordinate $y$ of the new transformed shape of the profile is obtained after calculating:

$$
\mathrm{y}=\mathrm{y} \cdot \cos \alpha-\frac{\mathrm{R} \cdot \operatorname{tg} \gamma \cdot \sin ^{2} \alpha}{\cos \alpha}
$$

Coordinate $z$ of the new transformed shape of the profile is obtained after calculating:

$$
\mathrm{z}=\mathrm{R} \cdot \frac{\sqrt{\mathrm{P}}}{\cos \alpha}-\mathrm{R}_{\mathrm{R}}
$$

The change of position of the touch point in the $x$ direction we obtain by using the formula:

$$
\mathrm{x}=\mathrm{R} \cdot \operatorname{tg} \gamma \cdot \frac{\sin \alpha}{\cos \alpha}
$$

The following graphs shows the results of transformation calculation of the UIC S1002 wheel profile respect to the original shape of the profile. Behaviour of the touchpoint position by rotation of profile an angle of attack from 0 to 36 milliradians is on the following charts. The values of equivalent conicity with lateral amplitude of wheelset of $3 \mathrm{~mm}$ for different angles of attack are shown in next table.

Table 1. Angle of attack effect in milliradians to equivalent conicity at an amplitude of $3 \mathrm{~mm}$

\begin{tabular}{|c|c|c|c|c|c|c|c|c|}
\hline & $\begin{array}{c}\text { Angle of } \\
\text { Attack }\end{array}$ & $\begin{array}{c}\text { Equivalent } \\
\text { Conicity }\end{array}$ & $\begin{array}{c}\text { Angle of } \\
\text { Attack }\end{array}$ & $\begin{array}{c}\text { Equivalent } \\
\text { Conicity }\end{array}$ & $\begin{array}{c}\text { Angle of } \\
\text { Attack }\end{array}$ & $\begin{array}{c}\text { Equivalent } \\
\text { Conicity }\end{array}$ \\
\hline 1 & 0 & 0.180 & 6 & 20 & 0.180 & 11 & 44 & 0.183 \\
\hline 2 & 4 & 0.179 & 7 & 24 & 0.180 & 12 & 52 & 0.184 \\
\hline 3 & 8 & 0.179 & 8 & 28 & 0.180 & 13 & 60 & 0.185 \\
\hline 4 & 12 & 0.180 & 9 & 32 & 0.181 & 14 & 68 & 0.186 \\
\hline 5 & 16 & 0.180 & 10 & 36 & 0.182 & 15 & 76 & 0.187 \\
\hline
\end{tabular}




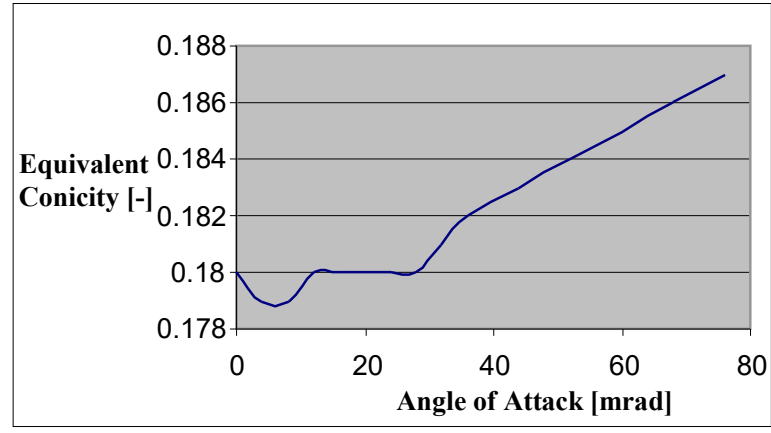

Fig. 2. Behaviour of equivalent conicity from angle of attack at an amplitude of $3 \mathrm{~mm}$

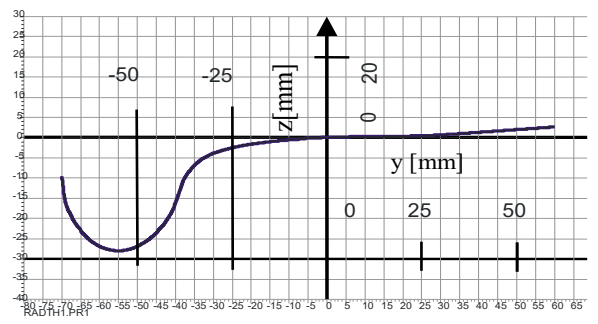

Fig. 3. Angle of attack $=0 \mathrm{mrad}$

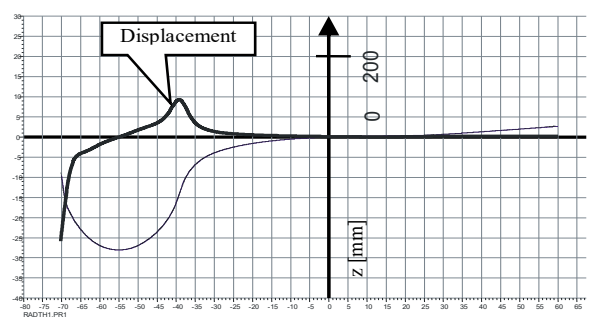

Fig. 4. Angle of attack $=4 \mathrm{mrad}$

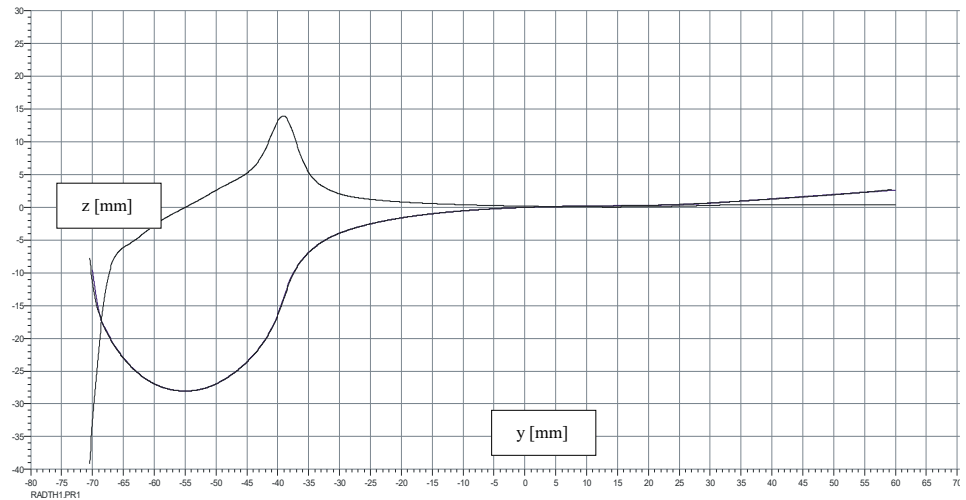

Fig. 5. Angle of attack $=8 \mathrm{mrad}$ 


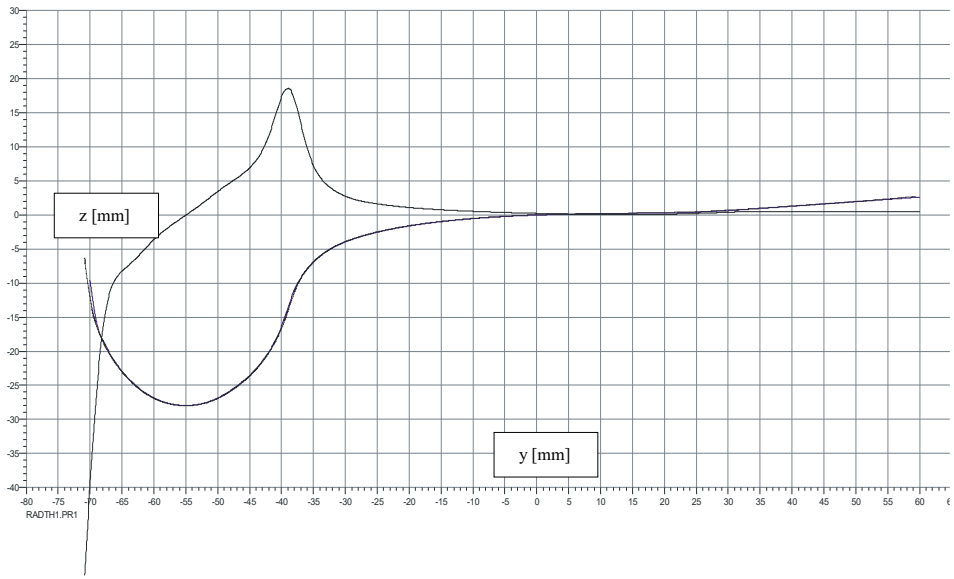

Fig. 6. Angle of attack $=12 \mathrm{mrad}$

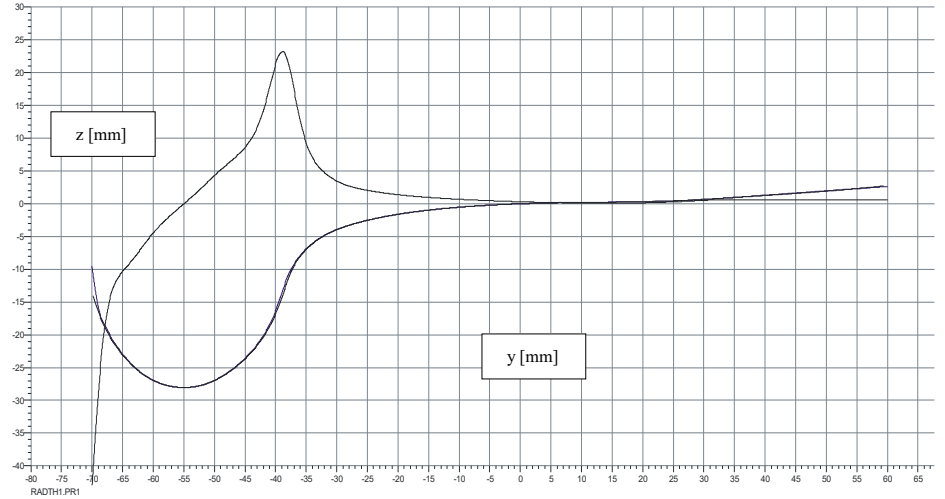

Fig. 7. Angle of attack $=16 \mathrm{mrad}$

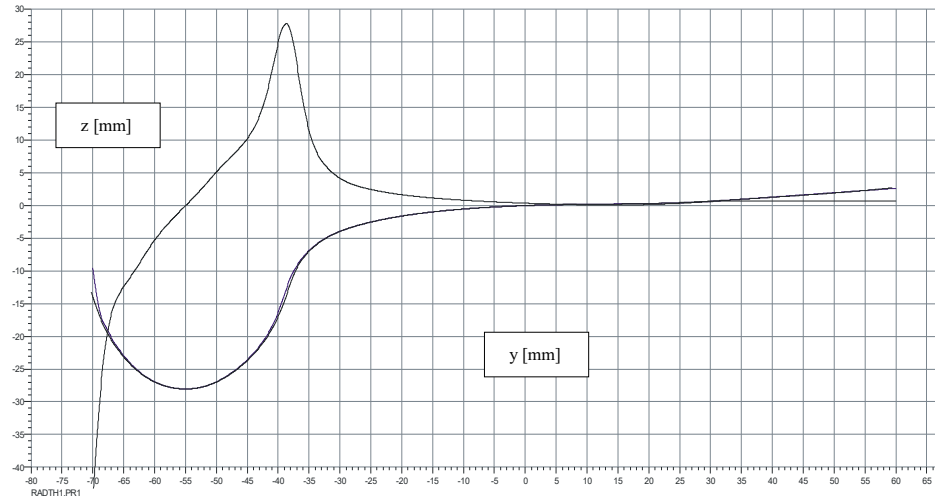

Fig. 8. Angle of attack $=20 \mathrm{mrad}$ 


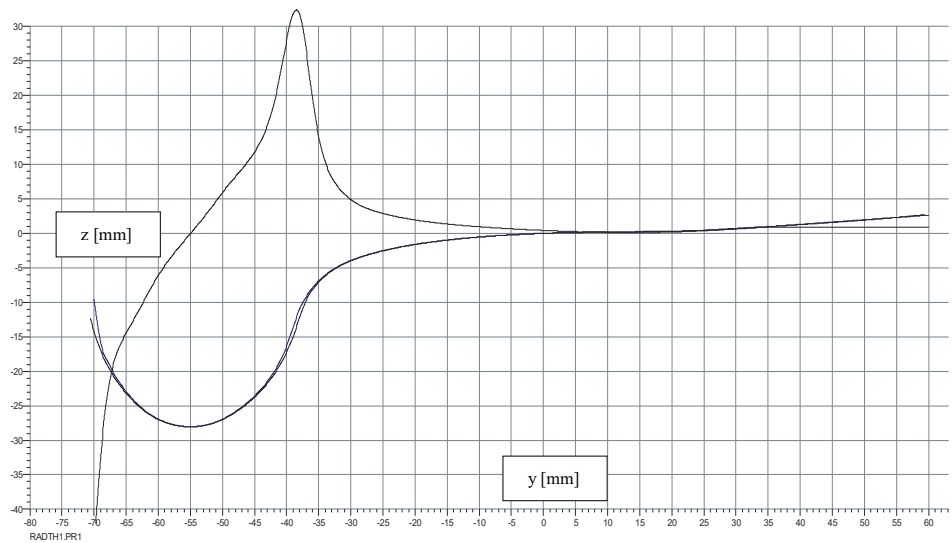

Fig. 9. Angle of attack $=24 \mathrm{mrad}$

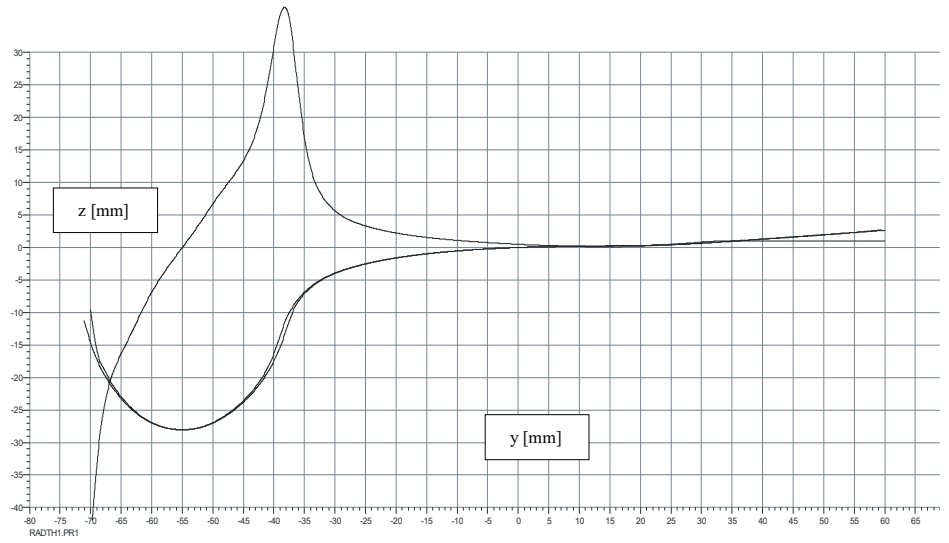

Fig. 10. Angle of attack $=28 \mathrm{mrad}$

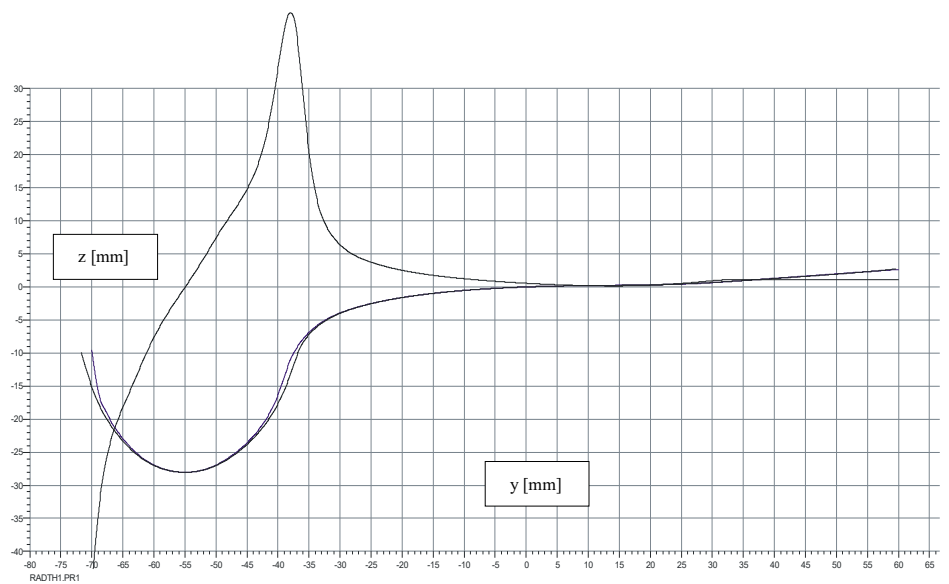

Fig. 11. Angle of attack $=32 \mathrm{mrad}$ 


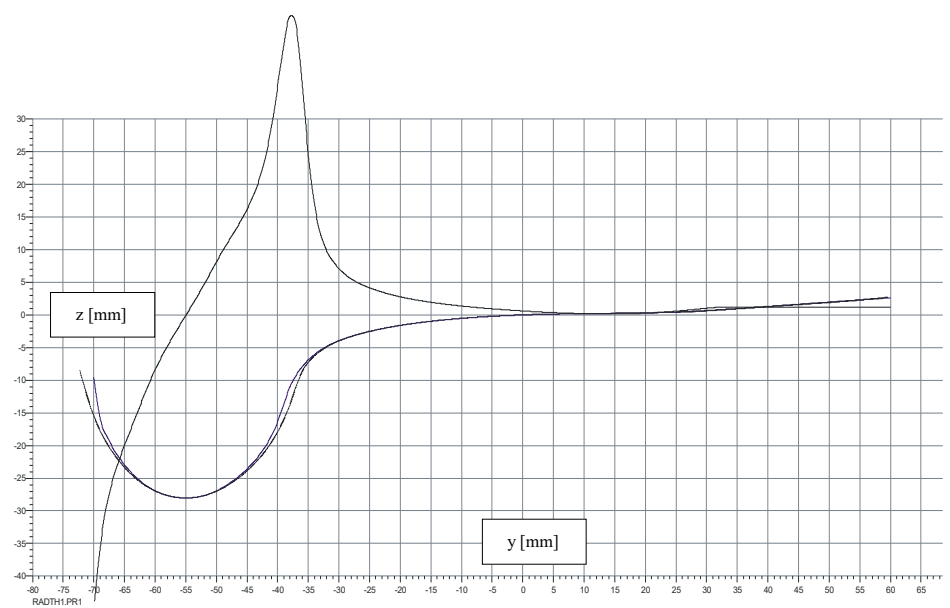

Fig. 12. Angle of attack $=36 \mathrm{mrad}$

\section{Conclusions}

The rail-wheel interface is fundamental to explain the dynamic running behaviour of a rail vehicle. In the case of a transverse displacement of the wheelset in the track (conical wheel surfaces) there is a change in instantaneous radii of rolling and to the tendency of the wheelset to perform movement in the arc. The axis of the wheelset is no longer perpendicular to the track axis, but is rotated under the angle of attack $\alpha$.

The aim of the research is to study the railway wheelset and rail contact problems via their analysis, via their geometrical binding as well as to specify properties of the binding with the help of the wheelset and rail contact geometrical characteristics.

The wheelset and rail contact determines a direct relationship between a vehicle and a rail. Through their relationship, the vehicle influences its surroundings and at the same time it transfers the influence of the surroundings to the vehicle.

The work was supported by the Cultural and Educational Grant Agency of the Ministry of Education of the Slovak Republic in project No. KEGA 077ŽU-4/2017: Modernization of the Vehicles and engines study program. The work was also supported by the project No. APVV-0842-11: Equivalent railway operation load simulator on the roller rig and VEGA No. 1/0558/18: Research of the interaction of a braked railway wheelset and track in simulated operational conditions of a vehicle running in a track on the test stand.

Research-Educational Center of Rail Vehicles (VVCKV)

\section{References}

1. J. Gerlici, T. Lack, Contact of a railway wheelset and a rail (in Slovak). Scientific monograph, ISBN 80-8070-317-5, EDIS - publishing house of University of Žilina, (2004)

2. J. Gerlici, T. Lack, Rail geometry analysis - from the point of view of wearing in the operation. Communications - Scientific Letters of the University of Žilina, ISSN 1335 4205. Vol. 5, No. 1, pp. 43-51 (2003) 
3. J. Gerlici, T. Lack, Railway wheel and rail geometry influence on ride properties of the vehicle (in Slovak). 16. International Conference PRORAIL 2003 - Current problems in rail vehicles, Universtity of Žilina, ISBN 80-968823-6-8, pp. 163-171 (2003)

4. J. Gerlici, T. Lack, M. Kadorová, Calculation of the equivalent conicity function of the railway wheelset tread profile at the Delta $R$ function with a negative slope. Communications - Scientific Letters of the University of Žilina, ISSN 1335-4205. Vol. 6, No. 2, pp. 49-56 (2004) 